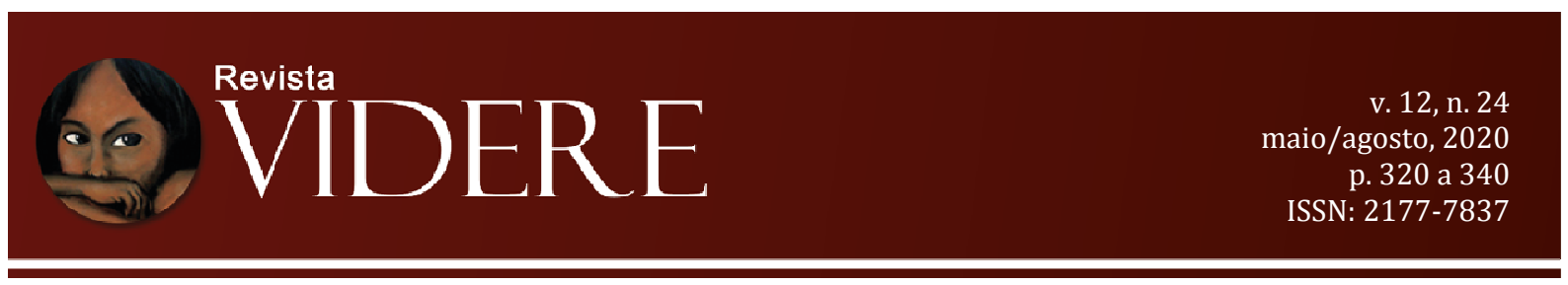

\title{
ARQUITETURA FORENSE E O CASO AYOTZINAPA: UMA ESTÉTICA INVESTIGATIVA A PARTIR DAS LEITURAS DE ZAFFARONI E DIDI-HUBERMAN
}

\author{
FORENSIC ARCHITECTURE AND THE AYOTZINAPA CASE: \\ AN INVESTIGATIVE AESTHETICS FROM THE READINGS OF \\ ZAFFARONI AND DIDI-HUBERMAN
}

\author{
Renato Duro Dias \\ Doutor em Educação (UFPEL), Brasil \\ Professor da Universidade Federal do Rio Grande \\ (FURG), Brasil \\ E-mail: renatodurodias@gmail.com \\ OrcID: http://orcid.org/0000-0002-9849-1332
}

\author{
Herson Alex Santos \\ Mestre em Direito (FURG), Brasil \\ E-mail: herson_alex@outlook.com \\ OrcID: http://orcid.org/0000-0002-0998-4654
}

\begin{abstract}
RESUMO: Tendo como referência artística a exposição Forensic Architecture - hacia una estética investigativa realizada no Museu Universitário de Arte Contemporânea (MUAC) da Universidad Nacional Autónoma de México (UNAM) em 2017, o presente artigo problematiza as implicações destes estudos imagéticos e investigativos para o campo da criminologia. Neste sentido, trata-se de um estudo de abordagem qualitativa, de revisão bibliográfica e de análise de conteúdo e imagens, que pretende reflexionar sobre questões sociais emergentes, como a violência pública e violência estatal, lançando luzes sobre aspectos teóricos de modo transdisciplinar. A partir da necessidade de se ouvir as palavras dos mortos, conceito utilizado por Zaffaroni (2012) e a emergência dos estudos de DidiHuberman (2004), em especial o dedicado a analisar as fotos (imagens) e as memórias do Holocausto, este estudo se debruça em pensar múltiplos caminhos e possibilidades, a fim de compreender os dias de setembro de 2014, nos quais estudantes da Escola Normal Rural de Ayotzinapa foram atacados pela polícia local em conluio com organizações criminosas, deixando como memória seis (06) pessoas mortas, quarenta (40) feridas e quarenta e três (43) estudantes desaparecidos. Desta forma, este escrito busca articular o trabalho investigativo do Forensic Architecture no interior da Criminologia Cautelar (ZAFFARONI, 2012), procurando oferecer elementos para reflexionar sobre as interfaces entre os campos da criminologia, da investigação criminal, das artes e dos estudos visuais.
\end{abstract}

PALAVRAS-CHAVE: Forensic Architecture. Ayotzinapa. Criminologia Cautelar. Zaffaroni. Didi-Huberman. 
ABSTRACT: Taking the Forensic Architecture - for an investigative aesthetic exhibition as an artistic reference, held at the University Museum of Contemporary Art (MUAC) of the Universidad Nacional Autónoma de México (UNAM) in 2017, this article discusses the implications of these imaging and investigative studies for the field of criminology. It is a study of qualitative approach, bibliographic review and content and image analysis that aims to reflect on emerging social issues such as public violence and state violence, shedding light on theoretical aspects in a transdisciplinary way. From the need to listen to the words of the dead, a concept used by Zaffaroni (2012) and the emergence of Didi-Huberman's studies (2004), especially the one dedicated to analyze the photos (images) and the memories of the Holocaust, this study focuses on thinking about multiple paths and possibilities, in order to understand the days of september 2014, in which students from the Ayotzinapa Rural Normal School were attacked by the local police in collusion with criminal organizations, leaving six (06) people dead, forty (40) injured and forty-three (43) missing students. Thus, this writing seeks to articulate the investigative work of Forensic Architecture within the Criminology Cautelar (ZAFFARONI, 2012) seeking to offer elements to reflect on the interfaces between the fields of criminology, criminal investigation, the arts and visual and imagery studies.

KEYWORDS: Forensic Architecture. Ayotzinapa. Cautionary Criminology. Zaffaroni; DidiHuberman.

\section{Introdução - O Caso Ayotzinapa}

O presente artigo problematiza as implicações dos estudos imagéticos e investigativos para o campo da criminologia, tendo como ponto de partida a exposição Forensic Architecture - para uma estética investigativa ${ }^{150}$ realizada no Museu Universitário de Arte Contemporânea (MUAC) da Universidad Nacional Autónoma de México (UNAM), em 2017.

Desta forma, este estudo se debruça em pensar múltiplos caminhos e possibilidades a fim de compreender os dias de setembro de 2014, nos quais estudantes da Escola Normal Rural de Ayotzinapa (região de Guerrero, México) foram atacados pela polícia local em conluio com organizações criminosas, deixando como memória seis (06) pessoas mortas, quarenta (40) feridas e quarenta e três (43) estudantes desaparecidos.

\footnotetext{
${ }^{150}$ Tradução livre. Disponível em: https://muac.unam.mx/exposicion/forensic-architecture . Acesso em: 03 de março de 2020 .
} 
O CASO AYOTZINAPA: Uma Cartografia da Violência. Na noite do dia 26 para o dia 27 de setembro de 2014, estudantes da Escola Normal Rural de Ayotzinapa foram atacados na cidade de Iguala, Guerrero, pela polícia local em conluio com organizações criminosas. Vários outros ramos do aparato de segurança mexicano participaram ou testemunharam os eventos, incluindo a polícia estadual, a federal e os militares das forças armadas. Seis pessoas foram assassinadas, incluindo três estudantes. Outros quarenta ficaram feridos e quarenta e três estudantes desapareceram. O paradeiro dos estudantes desaparecidos permanece desconhecido e seu status de "desaparecido" persiste até hoje. Em vez de tentar resolver esse crime histórico, o Estado mexicano falhou com as vítimas e com o resto da sociedade mexicana, construindo uma narrativa fraudulenta e inconsistente sobre os acontecimentos daquela noite. (FORENSIC ARCHITECTURE, 2017)

Justiça mexicana afirma que os 43 estudantes de Ayotzinapa foram executados. Os 43 estudantes da escola rural do magistério de Ayotzinapa, do Estado de Guerrero (México), cujo paradeiro é desconhecido desde 26 de setembro de 2014, não foram vítimas de um desaparecimento forçado, e sim executados, afirmaram juízes federais em uma série de sentenças difundidas no sábado pelo jornal mexicano Reforma. Os indícios analisados pela Promotoria Geral, de acordo com os juízes, sugerem que os 43 estudantes foram vítimas de uma execução sumária, ou seja, foram julgados, condenados e executados de uma só vez, como em um fuzilamento. Ao descartar o crime de desaparecimento forçado, as instâncias judiciais recusaram emitir ordens de busca e apreensão contra os 56 acusados, entre eles o ex-prefeito de Iguala, José Luis Abarca e sua esposa, María de los Ángeles Pineda (suspeitos de terem mandado matar os estudantes), os policiais municipais de Iguala e Cocula, e supostos membros do cartel Guerreros Unidos. Na época, 120 políticos locais, policiais, supostos narcotraficantes e informantes foram detidos pelo caso de Iguala, mas a Promotoria não atribuiu responsabilidades a nenhum dos acusados pelo sequestro. (EL PAÍS, 15/05/2016).

Neste sentido, trata-se de um estudo de abordagem qualitativa, de revisão bibliográfica e de análise de conteúdo e imagens que pretende reflexionar sobre questões sociais emergentes como as violências pública e estatal, lançando luzes sobre aspectos teóricos de modo transdisciplinar. A partir da necessidade de se ouvir as palavras dos mortos, conceito utilizado por Zaffaroni (2012), e a emergência dos estudos de Didi-Huberman (2004), em especial o dedicado a analisar as fotos (imagens) e as memórias do Holocausto. Assim, este escrito busca articular o trabalho investigativo do Forensic Architecture no interior da Criminologia Cautelar (ZAFFARONI, 2012), procurando oferecer elementos para refletir sobre as interfaces entre os campos da criminologia, da investigação criminal, das artes e dos estudos visuais. 
[...] Em uma decisão sem precedentes, a Primeira Collegiate Tribunal do Circuito XIX, com sede em Ciudad Reynosa, Tamaulipas, definiu como a decisão como um "reiniciar procedimental" da investigação porque "não há provas suficientes para presumir que as confissões e acusações" daqueles que interpuseram apelações de amparo - vários acusados de participar dos desaparecimentos - foram "obtidas por meio de tortura", entre outras irregularidades. Uma investigação indica que as prisões podem ser devidas ao fato de que um dos ônibus levados pelos estudantes tinha drogas de um grupo rival de narcotraficantes sem o conhecimento dos estudantes, mas isso não foi confirmado. [...] (NEW YORK TIMES, 04/06/2018).

É a partir deste caso que se inicia o presente estudo, no qual se busca discutir a atuação do grupo Forensic Architecture, bem como questionar: se a ação do grupo pode ser considerada como anunciação de massacres por parte do poder punitivo? Ou talvez, além desse possível pressuposto, se tal ação pode ser também considerada como segmento de uma criminologia cautelar? Na problematização dessas questões, cabe compreender o que é Criminologia Cautelar e. para isso, se utilizará a ótica de Zaffaroni (2012), que a contempla em correlação a uma necessária atenção para se ouvir a palavra dos mortos, tema também abordado por Didi-Huberman (2003), sob uma perspectiva imagética. Faz-se importante compreender de antemão, quem são estes mortos e o que eles têm a dizer, e qual cautela exige esta forma de se fazer criminologia.

Fugindo das abstrações, nas pegadas de Spee, o mais concreto que encontramos são os cadáveres. Ao incorporar os massacres à criminologia abrimos nossos olhos a uma realidade cadavérica e os criminólogos não podem se permitir ao luxo de postergá-la enquanto se perdem em especulações sobre as sociedades possíveis e as culturas futuras, tarefa que, ademais, é levada a cabo por aqueles dotados de melhores armas intelectuais que nós. Cautela provém do radical indo-europel keud, que indica prestar atenção, perceber, que em sânscrito deu origem a kaví, que significa inteligente, e em latim a caveo, estar em guarda. É a palavra exta, que não foi escolhida à toa por Spee. (ZAFFARONI, 2012, p. 463).

Entende-se salutar pensar novos caminhos, tanto às formas de investigação criminal quanto à cautela que toda nova tecnologia carece por ser inovadora e seus resultados ainda desconhecidos. Afinal, tais tecnologias são constituídas, ambivalentemente, como potencialmente probas às novas demandas em respeitos à vida e aos direitos humanos, e também às possibilidades massacradoras. Por isso, o passado historiográfico massacrador do poder punitivo norteia esta discussão que não pretende exaurir a temática, mas lançar mais luzes, perquirindo sobre a criminologia cautelar e sua função preventiva para, então, indagar se o caso Ayotzinapa poderia ter sido objeto de prevenção. 


\section{Contribuições dos estudos visuais para a investigação criminal (Criminologia e Direito)}

Na contemporaneidade o caráter transdisciplinar tem sido destaque para as produções nas mais variadas áreas do conhecimento. São, especialmente, as Ciências Sociais que têm se debruçado na análise de outros documentos como mecanismos investigativos. De acordo com Dias (2015, p. 396) “Atribui-se à imagem um poder discursivo intenso, explicitado, por vezes, nas ações e reações que o olho e o corpo humano demonstram ou somatizam". Assim, o uso das imagens sejam elas fixas (fotografia, pintura) ou móveis (cinema), possibilitam leituras de mundo e do contexto de modo peculiar, vale dizer, põe em evidência o caráter discursivo da mensagem visual.

No campo do direito, especialmente na criminologia cultural, estas pesquisas têm contribuindo para visualizar os aspectos culturais e, ao mesmo tempo, encaminhar importantes debates levantados pelos meios de comunicação (mídia), o cinema, a música e as artes visuais (SANTOS e DIAS, 2017, p. 40).

Neste espectro incluem-se os estudos realizados pelo Forensic Architecture - uma agência de investigação vinculada a Goldsmiths, University of London, que realiza pesquisas territoriais e de mídias avançadas em casos de violações de direitos humanos. A agência atua em consórcio com as comunidades afetadas pela violência policial, com organizações de direitos humanos, promotores internacionais e grupos de justiça ambiental. Seu trabalho está direcionado à produção e apresentação de evidências arquitetônicas e em ambientes urbanos, vinculando-se às investigações criminais que envolvem processos judiciais e políticos.

Criado em 2010, Forensic Architecture produz estudos para demonstrar a violência do Estado, especialmente nas violações em direitos humanos. $\mathrm{O}$ grupo usa a arquitetura como uma ferramenta metodológica para investigar conflitos armados e destruição ambiental. Por meio de modelos ${ }^{151}$ teórico-metodológicos, análise de vídeo, novas tecnologias, cartografias interativas e outros recursos, eles reconstroem os eventos de forma independente ou a pedido de várias ONGs, como é o caso frequente da parceria com a Anistia Internacional.

Como se pode perceber na fotografia abaixo, a exposição Forensic Architecture para uma estética investigativa apresenta um conjunto de estratégias visuais que permitem o espectador se inserir na proposta expositiva e ao mesmo tempo compreender as complexas redes de uma investigação criminal.

\footnotetext{
${ }^{151}$ Para detalhamento dos modelos ver Forensic Archicteure. Disponível em: https://forensicarchitecture.org/about/agency. Acesso em: 12 de março de 2020.
} 
$\mathrm{Na}$ exposição se analisam desde mapas detalhados com as rotas percorridas pelos estudantes desaparecidos, assim como, possíveis cenários envolvendo a polícia e as organizações criminosas imbricadas.

Forensic Architecture - para uma estética investigativa, 2017.

Visão panorâmica da exposição.

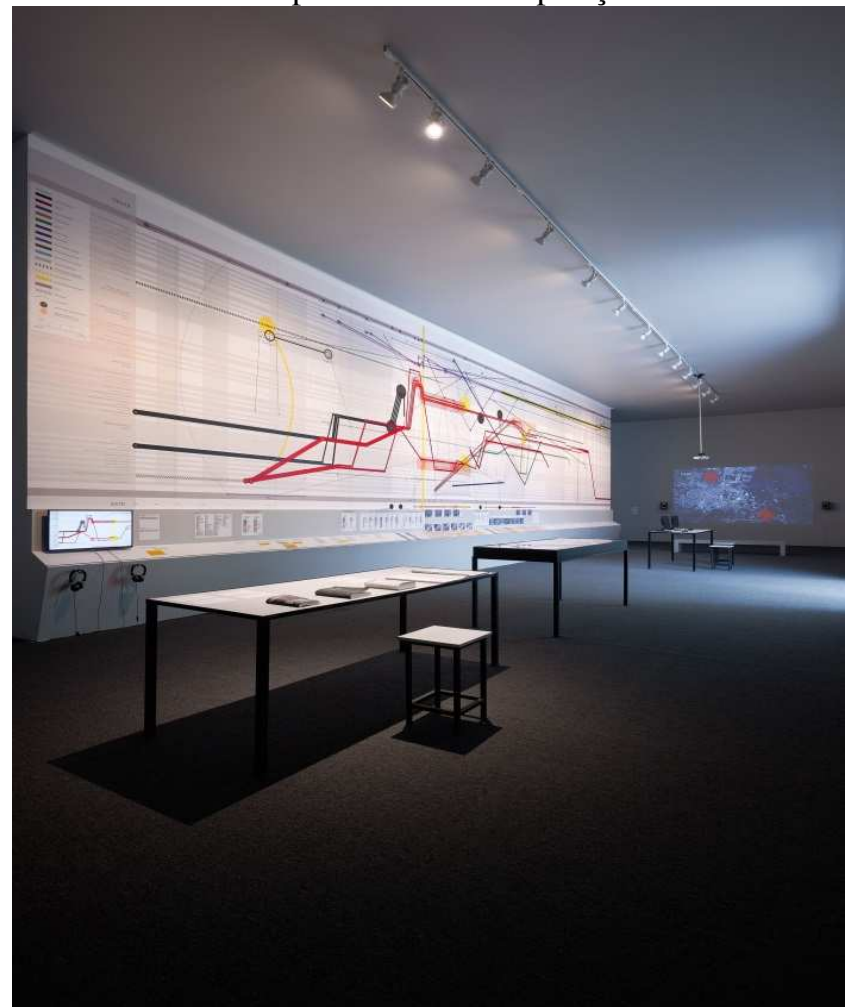

Fonte: MUAC/UNAM, 2017.

Neste sentido, a exposição Forensic Architecture - para uma estética investigativa provoca espectadores e pesquisadores na medida em que trata de questões sociais emergentes, especialmente fundamentais aos países latino-americanos.

Por outro lado, quando se discute os sistemas punitivos e as relações societárias impregnadas de violência, se faz necessário proceder a outros instrumentos investigativos para além dos parâmetros convencionais do direito. Neste sentido, este estudo de abordagem qualitativa com análise de imagens e de objetos visuais, pretende, primeiramente, reflexionar sobre questões sociais emergentes. (SANTOS e DIAS, 2017, p.40).

Os discursos presentes no campo dos estudos visuais podem contribuir para discutir as categorias como a violência policial e política, os mecanismos do Estado perpetuar suas intricadas redes de poder, inclusive a investigação criminal.

Os estudos do campo visual representam, atualmente, uma potente possibilidade que desloca para o centro o olhar sobre a visualidade. De cunho eminente interdisciplinar, os estudos através das imagens rompem 
com os recortes epistêmicos e com decisões compartimentadas, produzemse, assim, infinitas combinações e desdobramentos. (DIAS, 2015, p. 398)

Este texto visual, apresentado pelo Forensic Architecture, pode ser um importante "documento" (BOHNSACK, 2007) no contexto da produção do direito, entendido como um ponto de partida, a fim de compreender como o uso de outras linguagens, que não a escrita, enxergam o campo da criminologia.

O considerável desenvolvimento dos métodos qualitativos durante os últimos vinte anos está intrinsecamente relacionado à "virada lingüística" (linguistic turn) (sic). A presunção de que textos gravados constituem os dados básicos em todas as pesquisas científicas é conseqüentemente responsável por esta predominância dos métodos de interpretação de textos e por esta "fixação" particular sobre os textos no âmbito das metodologias qualitativas. [,,,] O método documentário de interpretação de imagens é um procedimento apropriado para o enfrentamento deste desafio. (BOHNSACK, 2007, p. 311).

A virada linguista e imagética possibilitam potencializar estas leituras de mundo, tendo como ponto de partida esses entrecruzamentos entre imagem e texto escrito.

\section{A Criminologia cautelar e os massacres anunciados}

O caso Ayotzinapa tornou-se emblemático, dentre tantos motivos, também pelo fato de contar com a participação de agentes públicos, sobretudo, da área de segurança do Estado, envolvidos direta ou indiretamente em mortes sistematizadas - uma chacina. Neste ponto, quando um massacre desta proporção conta com a participação de autoridades de diversos escalões e setores do funcionamento público - principalmente policiais -, não resta dúvida em afirmar que tais mortes pertencem à cifra dos mortos pelo poder punitivo.

Para Foucault, o maior alcance do poder punitivo não era tanto a prisionalização, mas sim o modelo panóptico que se estendia a toda a sociedade sob a forma de vigilância. Nisso ele tem toda razão, porque o simples poder de encarcerar ou libertar um número sempre muito reduzido, em relação ao total da população, de pessoas dos estratos mais subordinados da sociedade não implica o exercício de um poder politicamente muito significativo. (ZAFFARONI, 2012, p. 214).

Não é forçosa esta constatação pelo fato de que a polícia consiste no que se pode chamar de "poder secundário de criminalização". Sobre isso Zaffaroni (2006) afirma que 
A seleção não só opera sobre os criminalizados, mas também sobre os vitimizados. Isto corresponde ao fato de que as agências de criminalização secundária, tendo em vista sua escassa capacidade perante a imensidão do programa que discursivamente lhes é recomendado, devem optar pela inatividade ou pela seleção. Como a inatividade acarretaria seu desaparecimento, elas seguem a regra de toda burocracia e procedem à seleção. Este poder corresponde fundamentalmente às agências policiais. De qualquer modo, as agências policiais não selecionam segundo seu critério exclusivo, mas sua atividade neste sentido é também condicionada pelo poder de outras agências: as de comunicação social, as agências políticas etc... A empresa criminalizante é sempre orientada pelos empresários morais, que participam das duas etapas de criminalização; sem um empresário moral as agências políticas não sancionam uma nova lei penal nem tampouco as agencias secundárias selecionam pessoas que antes não selecionavam... O conceito de empresário moral foi enunciado sobre observações relativas a outras sociedades, mas na nossa pode ser tanto um comunicador social, após uma audiência, um político em busca de admiradores ou um grupo religioso à procura de notoriedade, quando um chefe de policia à acata de poder ou uma organização que reivindica os direitos da minorias etc. Em qualquer um dos casos, a empresa moral acaba desembocando um fenômeno comunicativo: não importa o que seja feito, mas sim como é comunicado. A reivindicação contra a impunidade dos homicidas, dos estupradores, dos ladrões e dos meninos de rua, dos usuários de drogas etc., não se resolve nunca com a respectiva punição de fato, mas sim com urgentes medidas punitivas que atenuem as reclamações na comunicação ou permitem que o tempo lhes dê a centralidade comunicativa. (ZAFFARONI, 2006, p.45).

Por outro lado, como dito na investigação de Forensic Architecture, o "desaparecimento" daquelas pessoas contou não somente com autoridades do Estado, mas também com auxílio de, "ao menos", um cartel de drogas. Neste sentido, levanta-se a questão se tais mortes, ainda assim, podem ser consideradas como mortes causadas pelo poder punitivo? Ainda sobre a seleção criminalizante e com reflexo nesta questão, escreve Baratta que

Os mecanismos da criminalização secundaria acentuam ainda mais o caráter seletivo do direito penal. No que se refere à seleção dos indivíduos, o paradigma mais eficaz para a sistematização dos dados da observação é o que assume como variável independente a posição ocupada pelos indivíduos na escala social. (2002. p. 165).

Essa acentuação da seleção do poder punitivo não se dá por acaso. Como se viu, corresponde aos estereótipos que são selecionados pelo poder de criminalização secundário. Essa seleção se dá pela ébvia não operabilidade do poder punitivo em seu projeto de garantir a paz. Afinal, não se podendo enfrentar a quantidade incalculável de delitos, as agencias do poder secundário, em sua seleção estereotipada vinculam todo o funcionamento das demais agencias e de praticamente todo poder punitivo, em conjunto, como visto também, com o 
empresariado moral e a larga difusão de tais estereótipos pelas agências midiáticas. A criação e perpetuação de tais estereótipos não se tratam de particularidade de um ou outro, mas sim de um conjunto de fatores, de uma dialética do estereótipo entre as agências secundárias e os empresários morais. É desse modo que

A seleção criminalizante secundária conforme ao estereótipo condiciona todo o funcionamento das agências do sistema penal, de tal modo que o mesmo se torna inoperante para qualquer outra clientela, motivo pelo qual: a) é impotente para os delitos do poder econômico (os chamados crimes "do colarinho branco"); b) também o é, de modo mais dramático, diante de conflitos muito graves e não convencionais, como uso de meios letais massivos contra a população indiscriminada, usualmente chamado terrorismo; c) torna-se desconcertado nos casos excepcionais em que há seleção de alguém que não se encaixa nesse quadro (as agências politicas e de comunicação pressionam os advogados, formulam questionamentos aos quais não sabe responder, destinam-se lhes alojamentos diferenciados nas prisões etc.). Em casos extremos, os próprios clientes não convencionais contribuem para a manutenção das agências, particularmente das cadeias, com o que o sistema atinge sua maior contradição. (ZAFFARONI, 2006, p. 46).

As agências estatais de criminalização secundária, ao darem ritmo e fôlego ao intricado processo de criminalização, podem, não raramente, tornarem-se ferramenta de controle, mas uma forma de controle a parte de seu motivo primeiro de ser, ou seja, o que está inscrito no discurso oficial. O controle não oficial, operado por tais práticas, é um agudecimento das formas de violência social, desde as simbólicas, até as que geram massacres. Como se salienta, não somente agências oficiais, ou estatais participam desta seleção, no entanto, também, agências midiáticas, no que se pode chamar como mainstream, ou grande mídia. 
Os atos mais grosseiros cometidos por pessoas sem acesso positivo à comunicação social acabam sendo divulgados por esta [grande mídia] como os únicos delitos e tais pessoas como os únicos delinquentes. A estes últimos é proporcionado um acesso negativo à comunicação social que contribui para criar um estereotipo no imaginário coletivo. Por tratar-se de pessoas desvaloradas, é possível associar-lhes todas as cargas negativas existentes na sociedade sob a forma de preconceitos, o que resulta em fixar uma imagem pública do delinquente com componentes de classes sócias, éticos, etários, de gênero e estéticos. $\mathrm{O}$ estereotipo acaba sendo o principal critério seletivo da criminalização secundaria; daí a existência de certas uniformidades da população penitenciária, associada a desvalores estéticos (pessoas feias), que o biologismo criminológico considerou causas de delitos quando, na realidade, eram causas de criminalização embora possam vir a tornarem-se causa do delito quando a pessoa acabe assumindo o papel vinculado ao estereotipo (é o chamado efeito reprodutor da criminalização ou desvio secundário) (ZAFFARONI, 2006. p.46).

Neste sentido, não somente as agências estatais podem vir a compor este complexo aparato de criminalização, mas também outras organizações, como grupos políticos, ONG's, etc. Em outras palavras, dentro desta imensa gama de possíveis e prováveis, participantes no processo de criminalização secundária, aquela que dita o fôlego e dá vida à ação estatal no campo macro da criminalização, estão inclusas as agências de governo, como o aparato policial e judiciário.

Além dessas, outras como as pertencentes à grande mídia ou em sintonia ao mainstream, e todos aqueles empresários morais que de alguma forma participam na formulação retórica e teórica da figura do criminoso.

Como, por exemplo, as possíveis rotas percorridas por estes indivíduos, ao que se retrata na exposição e figura abaixo.

Forensic Architecture - para uma estética investigativa, 2017.

Simulação - Caso Ayotzinapa 


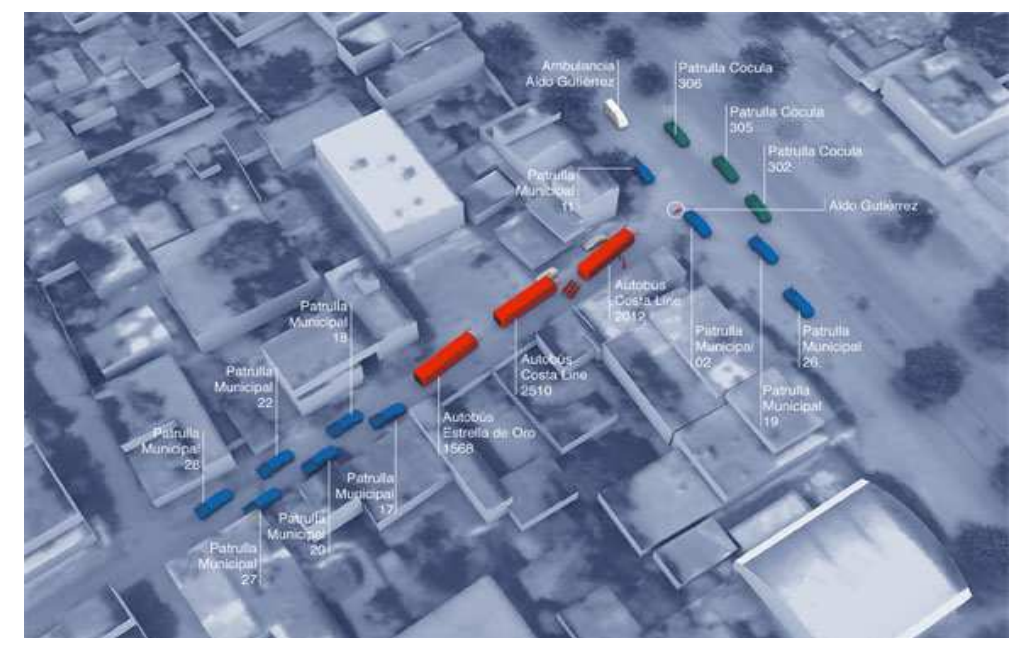

Fonte: MUAC/UNAM, 2017.

E, diante disso, retrocedendo às agências policiais, elas podem atuar em certa coordenação com organizações criminosas? A exposição e investigação criminal indicam que sim. E ganham força para a manutenção ou tomada de poder em determinados "grupos hegemônicos frágeis", pois existe "a hipótese de que os massacres não foram praticados por Estados fortes, mas sim por Estados frágeis, que procuram sair de suas crises reafirmando seu poder mediante estes massacres [...]" (ZAFFARONI, 2012, p. 372). Tal constatação pode ser mais pormenorizada, ao se analisar seus efeitos mais drásticos - os massacres, como no caso de Ayotzinapa. Isso porque, os massacres podem ser "instrumentos de grupos frágeis", tais massacres podem ser consequência de grupos hegemônicos que se sentem fragilizados (ZAFFARONI, 2012, p. 373).

Tendo em vista a questão de o massacre não contar unicamente com as agências policiais, mas também com pelo menos um cartel, torna-se visível que o poder secundário de criminalização, especificamente as agências policiais possuem um papel central neste processo de criminalização, funcionando não somente como ferramenta legítima do Estado, ainda atuando também, quando não somente, na manutenção de "grupos frágeis".

As agências policiais podem vir a tomar posição de tolerância, também de parceria ou de cumplicidade com poderes criminais como cartéis ou facções criminosas. Esses agenciamentos não acontecem somente no México, mas em vários países latino-americanos. Exemplos desses processos não faltam: houve no Brasil o caso do "esquadrão da morte", a título de exemplo histórico, que foi uma organização paramilitar do final dos anos 1960 que tinha como objetivo perseguir e matar criminosos tidos como perigosos para a sociedade, e que terminou com membros das forças policiais fazendo a segurança de indivíduos contraventores (DONNICI, 1990). Com a diminuição da ação dos esquadrões da morte no 
final da década de 1990, aconteceram, nos anos iniciais do novo século ${ }^{152}$, outras formas de atuação desse gênero que ganharam notoriedade na imprensa nacional com o nome de milícia. Atuante essa prática persiste, tal como geralmente era a ação dos esquadrões da morte, em comunidades de baixa renda e com o objetivo inicial de promover um combate ao crime sem a burocracia oficial, mas que descambou para práticas de extorsão da população por serviços básicos como gás, luz, dentre outros: televisão-a-cabo e bingos clandestinos. Tais organizações formadas majoritariamente por militares de várias esferas, inclusive corpo de bombeiros, geralmente contavam com auxílios de políticos e autoridades locais.

Nesta análise se faz necessário ressaltar que, apesar da polícia ser considerada uma agência do Estado, ela é antes de tudo uma instituição disciplinar de recrutamento de pessoas do mesmo estrato social onde habitam os estereótipos criminalizados, a margem socialmente vulnerabilizada (FOUCAULT, 2009). Portanto, quando há uma aproximação das ações entre agências policiais/militares e organizações criminosas, como no caso mexicano, está implícita está questão genealógica, de que ambos os atores, tanto os policializados, quanto os criminalizados, ou policiais e criminosos propriamente ditos, pertencem a um mesmo status vulnerável (SANTOS, 2019).

Do retorno ao caso Ayotzinapa, não é de todo difícil acreditar na possibilidade de interação entre as agências estatais e grupos criminosos. Para além dessa constatação, também não é de todo válido retirar tal massacre da cifra do poder punitivo por ele contar com auxílio direto ou indireto de organizações criminosas. Como se vê a supremacia do poder secundário de criminalização em seu desenrolar não exclui a possibilidade de interação entre agências estatais e a criminalidade lato sensu. Confirmando o que Michel Foucault (2009) afirmou ao compreender o poder enquanto exercício microfísico. Com tal interação, o poder secundário de criminalização desvenda, ainda mais, seu caráter seletivo e arbitrário. Desse modo, pode-se dizer que é demasiado ingênuo conceber o Direito Penal como um autômato desvinculado de toda e qualquer interferência política. Afinal é

\footnotetext{
${ }^{152}$ Apesar de tal atividade datar do início do século XXI, não se trata de algo propriamente novo, afinal há o exemplo na literatura que mostra algumas inferências desse tipo no Brasil do século XIX. Trata-se da obra de Manuel Antônio de Almeida de título "Memórias de um sargento de milícias (2011)". Além da mera nomenclatura, no enredo de tal obra se constata a precariedade do aparato militar-policial frente ao crime na cidade do Rio de Janeiro e também da característica pessoal marcante da personagem principal, Leonardo: um "bom malandro", figura típica do anti-herói, mas que pode ser encarado como um relato ou uma característica da sociedade da época sob o viés do estereótipo marginalizante, que, não por acaso, aproxima as figuras de criminoso e de policial na figura do "bom malandro", aquele vulnerabilizado esperto.
} 
Porque o Direito Penal encerra em si o uso estatal da violência, sua compreensão somente pode ser efetuada através da união de seus elementos técnicos com o seu significado político. Com efeito, a face politica do Direito Penal tão fortemente que ele é apontado como o mais sensível termômetro da feição politica do próprio Estado, isto é, se a violência da pena for aplicada de forma ilimitada, sem resguardar a Dignidade da Pessoa Humana, estaremos diante um Estado arbitrário; de outro lado, se a violência da pena for aplicada dentro de parâmetros de proporcionalidade (legalidade, culpabilidade etc.), de modo que se respeite a dita Dignidade da Pessoa Humana, estar-se-á ante a um Estado Democrático... Deste modo, não se pode desvincular o Direito Penal de um duplo viés: a aplicação e a interpretação constitucional (BRANDÃO, 2008. p.19).

Para além desta constatação de inferência política no Direito Penal, compreendem-se aqui as demais inferências, pois, no caso Ayotzinapa, por mais que se relativize a influência político-partidária no desaparecimento dos estudantes, o que é incontroverso é a atuação policial como último contato sabido entre os estudantes e o Estado mexicano.

Do delineamento satisfatório deste pressuposto - que as mortes e os desaparecimentos no caso Ayotzinapa correspondem à cifra de mortes do direito penal e não unicamente à criminalidade -, pode-se partir em busca da resposta a questão de que: seria possível prever tal massacre?

Zaffaroni (2012) afirma em sua conferência sobre criminologia cautelar que

a contabilidade cadavérica, descontando os mortos pelas guerras e os causados por negligência, demonstra que os Estados cometem mais homicídios dolosos - com dolo direto em primeiro e segundo grau e com dolo eventual - que todos os demais homicidas do planeta. (ZAFFARONI, 2012, p. 371).

Além deste alarmante dado, pode-se afirmar que, trata-se de uma forma de controle territorial que busca "[...] limpar e homogeneizar, higienizar, desinfetar [...]". Trata-se de uma técnica "[...] que começou dentro da própria Europa e que esta espalhou para o resto do mundo através do colonialismo e do neocolonialismo, até que no século passado, refluiu e voltou bruscamente para a Europa”. (ZAFFARONI, 2012, p. 371).

Se a partir das sinalizações sobre o poder punitivo criminalizante aqui trazidas, poder-se compreender que o agente do massacre é o próprio poder punitivo, então, a criminologia deveria se ocupar mais atentamente em observar este exercício punitivo, ou seja, o exercício particular das agências que executam e operam o sistema punitivo (ZAFFARONI, 2012, p. 407). Não é uma tarefa fácil reconhecer que o maior agente promotor de massacres é o próprio Estado, aquele mesmo que em sua tarefa principal deveria prevenir e combater 
homicídios. Contudo, apesar dessa dificuldade de se aceitar tal constatação, ela é, por demais, evidente (ZAFFARONI, 2012). Está evidência se constata pelo fato de sempre se ter atribuído à participação das agências de execução do poder punitivo nos massacres a alcunha de uma espécie de "patologia institucional". Porém, ademais do que uma mera patologia, o que se pode averiguar em um olhar historiográfico sobre tais agências executoras do poder penal, é que desde os séculos XI e XII, “[...] até o presente elas mostram manifestamente sua tendência a descontrolar-se, sob o pretexto de combater inimigos que geram a emergência de riscos iminentes para a humanidade." (ZAFFARONI, 2012, p. 408).

Zaffaroni compreende que a criação e a destruição dos inimigos ocorrem nas disputas entre as agências, pois é neste interstício, que se abre entre o emergir e o decair de agências no decorrer dos séculos, que se avançou enquanto "[...] discurso crítico do poder punitivo, ou seja, do direito penal de contenção ou redução, acompanhado pelo estado de direito daí decorrente, no plano político" (ZAFFARONI, 2012, p. 408).

Com isso, pode-se dizer que as mortes e o desaparecimento dos estudantes em Ayotzinapa, o possível massacre, em si, poderia não ser previsto. Contudo, diante do flerte capcioso, que se fazia e se faz evidente, diante dos aspectos de historicidade citados, entre as esferas políticas, policiais e criminosas, há que se falar em um anúncio de massacres. Portanto, o caso Ayotzinapa, está inserido neste anúncio, faz parte da grandiosa gama de massacres e que nem por isso deixaram de ocorrerem.

\section{Como ouvir as palavras dos mortos e interpretar suas imagens?}

Acredita-se aqui que o caso Ayotzinapa pode ser considerado um massacre. Além disso, por mais que pontualmente tal caso não pudesse ser evitado, dado seu enredo fático, a atenção à possibilidade de prevenção de massacres anunciados poderia ter dado outro desfecho a este massacre. $\mathrm{O}$ que as criminologias poderiam fazer, além de olhar de modo mais atento para estes vieses? Para Zaffaroni, as criminologias deveriam ouvir a palavra dos mortos, pois 
é certo que, embora não ocorra a sacralização da vítima, a mera possibilidade de inversão de sua avaliação que absorva o mérito da cessação da violência atua como uma ameaça inconsciente para os agentes do poder punitivo, que pode convertê-los em futuras vítimas sacrificiais. Daí seu temor dos cadáveres, das covas comuns, da incineração, das tumbas anônimas, da sepultura no mar. Destacamos, dias atrás, que os cadáveres voltam. (ZAFFARONI, 2012, p. 403).

Isso porque o contraste entre os saberes criminológicos e a palavra dos mortos deveria ser um horizonte ético cujas formas de se fazer criminologia nunca deveriam perder de vista, sob a pena de se converter discursivamente pessoas que ainda não estão mortas em cadáveres, como "vidas matáveis", "homo sacer" ou "vidas nuas" na acepção de Giorgio Agamben (2002). Trata-se de uma anunciação negativa que não impressiona, pois aqueles mortos ou com suas vidas desnudas não carecem, no interior da criminologia midiática, de valor moral, a não ser esporadicamente quando o dique rompe e um grande número de vítimas do poder punitivo não pode ser ignorado, passando a ser notícia por seu valor sensacionalista no mercado midiático.

Contudo, o problema em si não se esconde no fato de a mídia não os noticiar, isso mostra apenas o efeito de um acontecimento social muito maior, que impede também que a academia olhe para estes mortos e que ouça a suas vozes com a devida atenção (ZAFFARONI, 2012). Não ouvir esses mortos favorece a discursividade mortífera que erra, ora pelo excesso de abstração, ora por sua falta, que invariavelmente corrobora para um estado de coisa que propicia massacres, por ser permitido que o poder punitivo atue com demasiada autonomia, não somente sobre quem deve ou não ser preso, mas também sobre quem deve ou não morrer. $\mathrm{O}$ poder punitivo termina por operar de modo mortífero, como consequência dialética do silenciar das palavras dos mortos. Isso acontece em partes, porque "é certo que os cadáveres costumam estar longe dos teóricos", ou seja, "os teóricos são centrais e os mortos periféricos" (ZAFFARONI, 2012, p. 29).

A questão que se levanta então é: como ouvir os mortos e o que eles podem dizer? Primeiramente, "eles nos dizem que estão mortos, o que parece uma obviedade, mas não é porque as criminologias acadêmica e midiática costumam ignorá-los ou, ao menos, não levar em conta a imensa maioria deles" (ZAFFARONI, 2012, p. 28). Contudo, a questão de como os ouvir ainda precisa ser minimamente delineada, pois apesar deles não falarem propriamente, seu discurso é incontroverso ao afirmarem que estão mortos. Neste dizer não existe espaço para interpretações parciais, a hermenêutica cadavérica é uníssona, "[...] vemos que é inquestionável, que se trata de uma realidade e que a partir dessa realidade os cadáveres 
nos dizem algo, falam-nos a partir de seu mutismo e às vezes são demasiadamente eloquentes" (ZAFFARONI, 2012, p. 28).

Quando se abre escuta, depara-se com "[...] uma realidade cadavérica e os criminólogos não podem se permitir ao luxo de postergá-la enquanto se perdem em especulações sobre as sociedades possíveis e as culturas futuras" (ZAFFARONI, 2012, p. 463). Neste interim, a palavra exata a ser perseguida é cautela, no sentido de "prestar atenção, perceber". Este modo de se fazer criminologia cautelar, trata de uma militância. Este enfrentamento é de importância ímpar, pois tais guerreiros midiáticos não param, quando por vezes fracassam, reconstroem-se e reconstroem seu discurso com uma velocidade alucinante, quando fracassam em construir a imagem de um bode expiatório, prontamente encontram outro. Por este motivo que tal criminologia deve ser militante, ela deve ser vigilante "[...] para evitar a armadilha que nos lança o discurso que diz: bem, estes "eles" não, mas estes "eles" sim, são realmente maus” (ZAFFARONI, 2012, p. 467).

Observar, mais do que a belicosidade destes discursos, mas sua potencial desumanização de parcelas sociais que podem vir a se tornar vítimas dos massacres consentidos, como no caso dos conta-gotas dos presídios é um passo, nessa importante observação militante, pois ignorar sua facticidade culmina de modo incontroverso como no caso Ayotzinapa. Afinal o hipertrofiado poder punitivo marginal tende a aniquilar aqueles alvos selecionados como maus pela criminologia midiática e pelos empresários morais, mas quando este mesmo poder punitivo se volta contra outros atores não convencionais do tecido social, não se trata de um equívoco, trata-se do inchaço de um poder punitivo mortífero que segue os estereótipos e opera na lógica binária do bem contra o mal, do nós contra eles.

No mesmo sentido, quando Didi-Huberman (2004, p. 09) nos interroga "ver uma foto pode nos ajudar a conhecer melhor nossa história?" Com certeza. É o que afirma quando se refere as quatro fotografias do Holocausto utilizadas em sua obra.

Eu acrescentaria que essas fotos fazem parte de um conjunto de decisões tomadas por essas pessoas, esses prisioneiros, enterrados na terra. São fotos que fizeram explodir uma câmara de gás. É uma insurreição, essa imagem faz parte de um gesto de insurreição, apesar do que ela representa. E a grande pergunta destas imagens extremas seria essa: quando não há nada, quando não há nenhum meio para lutar, quando se está totalmente em atitude de humilhação, como, de alguma maneira, se subleva? Isso está claro. (DIDI-HUBERMAN, 2017) 
O que Didi-Huberman quer a partir destas quatro fotografias é produzir uma fenomenologia, que compreenda a necessidade destas imagens (caráter memorial), no passado, no presente e, especialmente, para o futuro. Essa análise envolve questionar as condições sob as quais uma fonte visual pode ser usada pela história.

A fotografia, como fonte visual, explora o silêncio, o que não é dito. Assim, vislumbra-se nestas imagens exploradas na obra de Didi-Huberman (2004).

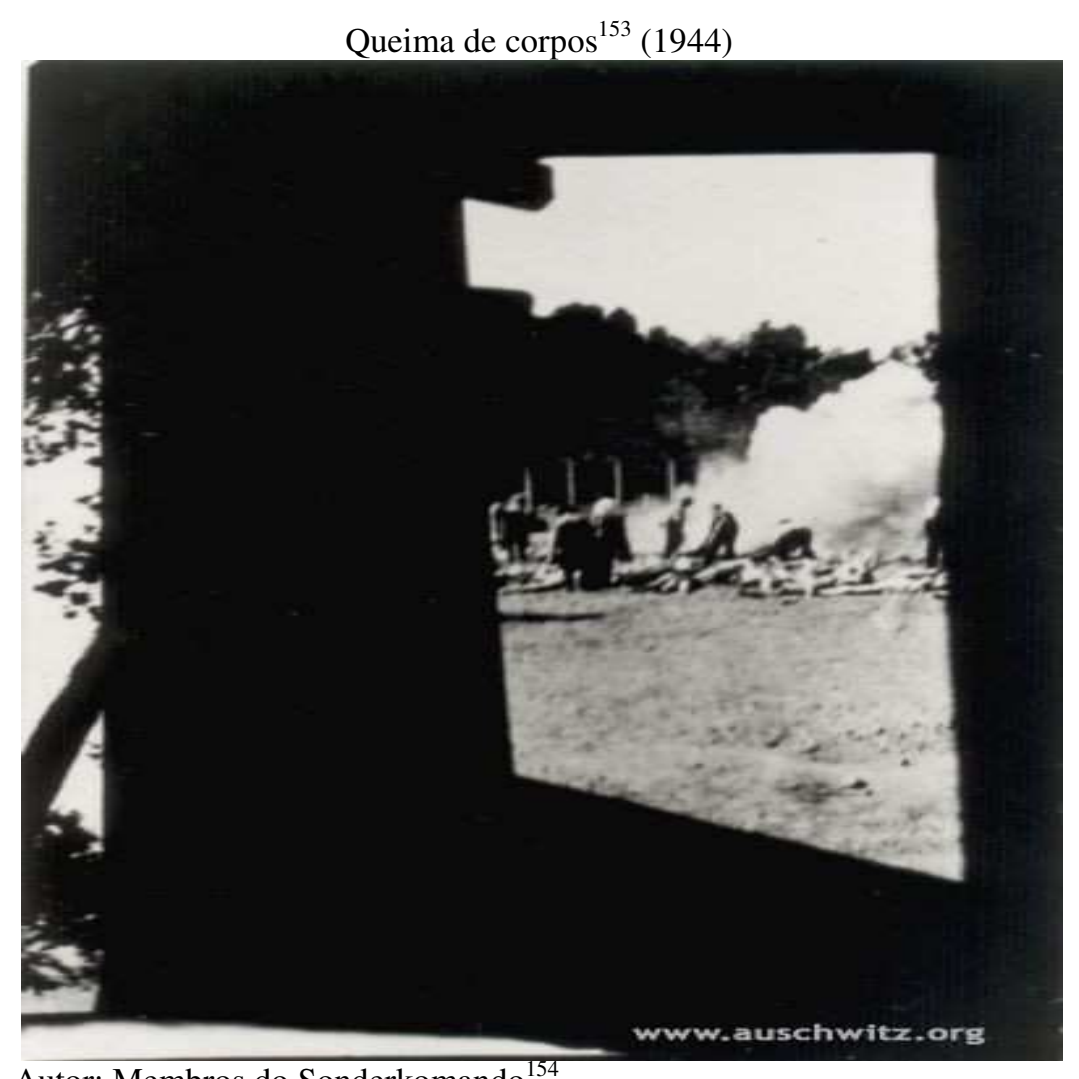

Autor: Membros do Sonderkomando ${ }^{154}$.

Fonte: Memorial and Museum Auschwitz-Birkenau, 2020

Essas imagens que mostram pilhas de corpos, muitos deles mutilados, outros a caminho das câmaras de gás ou dos incineradores são a prova (isto foi) desta barbárie. Essa memória visual do Holocausto produzida por Didi-Huberman (2004), a partir de fotos tomadas pelos Sonderkommandos (grupo de pessoas que operavam os campos de concentração nazista, em geral judeus), aponta a urgência de mostrar imagens sobre o “inimaginável”. A imagem "pode tocar a realidade, apesar de tudo, e assim separar as telas do fetichismo" (DIDI-HUBERMAN, 2004, p. 34).

\footnotetext{
153 Tradução livre de "Burning of bodies". Mostra corpos em chamas de vítimas de extermínio em massa em Auschwitz II-Birkenau.

${ }^{154}$ Uma das quatro (04) fotografias utilizadas por Didi-Huberman (2004).
} 
Ei-la, mais que em outro lugar qualquer, essa perspectiva aterradora. É o caminho a "estrada do campo" chamada pelos funcionários nazistas de Lagerstrasse. A que levava seja para o Zentralsauna, no caso dos "aptos", que teriam as roupas confiscadas e seriam desinfetados pelo Zyklon B, tatuados etc.; seja para os crematórios Ivev, no caso dos "inaptos", fadados à asfixia sumária por gás mediante doses mortais do mesmo Zyklon B. Outro caminho, chamado Hauptstrasse ou estrada principal, dirigia os "inaptos" recém-chegados para os grandes crematórios II e III. Foi nessa estrada, após a "triagem" na Judenrampe, que um funcionário nazista se posicionou, entre maio e junho de 1944, para fotografar os judeus húngaros saindo em comboio, em especial os tais "inaptos" - mulheres, crianças, idosos -, estes conduzidos diretamente para a morte. (DIDI-HUBERMAN, 2017, p. 106).

Didi-Huberman expõe de modo magistral, a descrição do que eram os passos trilhados pelos judeus nos campos de concentração. Essa escrita permite narrar o sofrimento, as dores e as mortes geradas em um período de exceção. A imagem toca, produz sensação.

\section{Considerações finais}

Diante do exposto, pode-se pensar sobre o trabalho da Forensic Architecture e questionar se suas empreitadas são próximas de uma criminologia cautelar ou se tratam de uma forma de revelação pormenorizada de tais massacres? Sendo a Forensic Architecture um grupo de pesquisa multidisciplinar, liderado pelo arquiteto Eyal Weizman, vinculada Universidade de Londres que utiliza técnicas e tecnologias de arquitetura para investigar casos de violência do Estado e violações de direitos humanos em todo o mundo pode estar contida nas duas assertivas. De modo mais evidente, como uma ferramenta criminológica apta às revelações massacradoras existentes por trás de massacres cujas investigações são "inconclusivas" ou até mesmo quando a própria possibilidade de morte não se pode ser auferida formalmente pela falta de materialidade do evento, como no caso Ayotzinapa onde 43 estudantes estão com status de "desaparecidos". Contudo, esta ferramenta pode constituir um marco efetivo na prevenção de massacres anunciados?

Pare responder esta questão vale lembrar que o fato de tal grupo de pesquisa existir já denota a problematização com massacres ocorridos, pois, uma vez que tal grupo age nos crimes de Estado contra os Direitos Humanos, emerge a noção de não resolutividade que tais crimes tendem a ter. Uma vez que os Estados modernos, com o monopólio da violência legítima, usam suas prerrogativas para fazerem, nas microrrelações de poder, ações atentárias contra grupos vulnerabilizados. Sobre isso Zaffaroni (2012, p. 403) diz que "silenciamos quando o poder punitivo rompe os diques de contenção jurídica do direito penal e eclode em 
massacres, cujos atores são precisamente os que, segundo o discurso, têm a função de preveni-los". Como exemplo, a capacidade da Forensic Architecture em revelar massacres pode ser experimentada no caso Ayotzinapa, já que "O projeto tem como objetivo reconstruir, pela primeira vez, a totalidade dos eventos conhecidos que ocorreram naquela noite em Iguala e arredores e fornecer uma ferramenta forense para os pesquisadores continuarem a investigação" (FORENSIC ARCHITECTURE, 2017).

Desta forma, "o projeto revela uma cartografia de violência que vai desde o nível das esquinas até todo o estado de Guerrero. Descreve um ato de violência que não é mais um evento singular, mas um ato prolongado, que persiste até hoje". (FORENSIC ARCHITECTURE, 2017)

Diante disso, Zaffaroni ao falar sobre o papel ativista e atento de uma criminologia cautelar, não parece forçoso considerar o papel da Forensic Architecture como uma ferramenta que não apenas escuta a palavra dos mortos, mas também os dá voz, ou ao menos uma segunda chance de serem escutados, não somente com o seu discurso cadavérico da facticidade de sua morte, mas também como vítimas da violência punitiva.

Neste sentido, considerar a Forensic Architecture como uma ferramenta reveladora de massacres é um pressuposto claro que pode, sem grande esforço, ser expandido para uma noção de prevenção de massacres anunciados, pois a Forensic Architecture ao se propor a fazer cartografias de crimes aparentemente insolúveis e com fortes indícios de violência e arbitrariedade estatal contra os direitos humanos, faz com que se possam ouvir aquelas vozes que, geralmente, são silenciadas tanto em vida quanto depois da morte pelo poder punitivo e, principalmente, pela criminologia midiática.

Nesta direção, Forensic Architecture pode não ser considerada uma promotora direta da criminologia cautelar no sentido acadêmico de produção textual, mas enquanto ferramenta hábil, possível de ser encampada nesta produção, parece probo propor que ela seja preventora de massacres anunciados ao demonstrar as sinuosas promiscuidades que o poder instituído tem com formas de poder paralelo, portanto ilegais, demonstrando que não se trata de um evento isolado em certa localidade do mundo, mas sim um modus operandi que assola os Estados Modernos por se ligar às praticas neocoloniais de acúmulo de capital, atuante especialmente, e de modo mais cruel, nos Estados periféricos.

Zaffaroni (2012, p. 403) adverte "Sabemos que a busca ansiosa por poder ilimitado gera massacres, que o saber do dominus o aprimora e ameaça a vida humana, que a exploração da vingança acaba no Estado policial e em massacre, mas não podemos neutralizar sua investigação". Pode se concluir que Forensic Architecture auxilia, além das revelações de 
massacres, na prevenção de mortes ao consistir uma ferramenta hábil na escuta das palavras dos mortos em seu discurso incontroverso, pois além de dar azo a tal escuta, o Forensic Architecture propicia em sua tarefa elucidativa uma segunda chance de audiência às vozes sistematicamente silenciadas pelo descaso social, pela criminologia midiática e pelo poder punitivo.

O caso Ayotzinapa fornece um exemplo incontroverso de atuação do grupo Forensic Architecture e a exposição visual, um instrumento de representação desta potente investigação. Esta investigação procura desvelara a importante discussão sobre os limites e a atuação do poder punitivo, bem como seus afluentes e consequências. Num sentido mais particular, especialmente com as contribuições de Zaffaroni e Didi-Huberman procurando oferecer elementos para reflexionar sobre as interfaces entre os campos da criminologia, da investigação criminal, das artes e dos estudos visuais.

\section{Referências}

AGAMBEN, Giorgio. Homo sacer: o poder soberano e a vida nua. Belo Horizonte: Editora UFMG, 2002.

ALMEIDA, Manuel Antônio de. Memórias de um sargento de milícias. Brasília: Centro de Documentação Informações, Edições Câmara, 2011.

BARATTA, Alessandro. Criminologia crítica e critica do direito penal: introdução à sociologia do direito penal. Rio de Janeiro: Revan, 2002.

BOHNSACK, Ralf. A interpretação de imagens e Método Documentário. In: Sociologias, Porto Alegre, ano 9, no 18, jun./dez. 2007, p. 286-311. Disponível em: http://www.scielo.br/pdf/soc/n18/n18a13.pdf . Acesso em: 12/03/2020.

BRANDÃO, Claudio. Curso de direito penal: parte geral. Rio de Janeiro: Forense, 2008.

DIAS, Renato Duro. Séries de animação: diálogos entre direito, arte e cultura popular. GT Direito, Arte e Literatura. Anais do XXIV Encontro Nacional do CONPEDI - UFS. Florianópolis: CONPEDI, 2015. Disponível em: http://conpedi.danilolr.info/publicacoes/c178h0tg/4d9nht62/m6Jz7T6Nrh3TVZMJ.pdf Acesso em: 12/03/2020.

DIDI-HUBERMAN, Georges. As imagens não são apenas coisas para representar. Entrevista com Georges Didi-Huberman. IHU On-line, 20/06/2017. [Entrevista cedida a] Verónica Engler, publicada por Página/12, 19/06/2017. Traduzida por André Langer. Disponível em: http://www.ihu.unisinos.br/186-noticias/noticias-2017/568830-as-imagens-nao-sao-apenascoisas-para-representar-entrevista-com-georges-didi-huberman Acesso em: 05/03/2020.

. Cascas. São Paulo: Editora 34, 2017. 
. Image malgré tout. Collection Paradoxe. Paris, France; Les Édition de Minuit, 2004.

DONNICI, Virgílio L. Polícia, guardiã da sociedade ou parceira do crime?: um estudo de criminologia. Rio de Janeiro: Forense universitária, 1990.

FORENSIC ARCHITECTURE - hacia una estética investigativa. Museu Universitário de Arte Contemporânea (MUAC), Universidad Nacional Autónoma de México (UNAM), México D.F. 2017. Disponível em: https://muac.unam.mx/exposicion/forensic-architecture Acesso em: 05/03/2020.

FOUCAULT, Michel. A microfísica do poder. Rio de Janeiro: Edições Graal, 2009.

Justiça mexicana afirma que os $\mathbf{4 3}$ estudantes de Ayotzinapa foram executados. Juízes federais descartam o delito de desaparecimento forçado durante a noite em Iguala e reforçam a teoria de homicídio. El País, Brasil. 15/05/2016. Caderno Internacional. Disponível em: https://brasil.elpais.com/brasil/2016/05/15/internacional/1463275908 978939.html?rel=mas. Acesso em: 12.03.2020.

Membros do Sonderkomando. Burning of Bodies. Memorial and Museum AuschwitzBirkenau. Disponível em: http://auschwitz.org/en/gallery/historical-pictures-anddocuments/extermination, 11.html. Acesso em: 12/03/2020.

SANTOS, Herson Alex; DIAS, Renato Duro. Possíveis intersecções entre criminologia cultural e artes visuais. Revista de Direito, Arte e Literatura. Brasília, v. 3, n. 1, p. 39 -57, jan/jun.2017. Disponível em:

https://www.indexlaw.org/index.php/revistadireitoarteliteratura/article/view/2189 . Acesso em: 05/03/2020.

SANTOS, Herson Alex. Vulnerabilidades: uma genealogia dos corpos dóceis policializados e criminalizados no contexto brasileiro. Orientador: Renato Duro Dias. 2019. Dissertação. (Mestrado em Direito e Justiça Social) - Universidade Federal do Rio Grande - FURG. Rio Grande, RS, 2019. Disponível em:

https://sistemas.furg.br/sistemas/sab/arquivos/bdtd/0000012994.pdf. Acesso em: 12.03.2020.

WEIZMAN, Eyal. Forensic Architecture. Universidade de Londres, Goldsmiths - UK, 2019. Disponível em: https://forensic-architecture.org/about/agency. Acesso em: 05/03/2020.

ZAFFARONI, E. Raúl. A palavra dos mortos: conferências de criminologia cautelar. São Paulo: Saraiva, 2012.

Revan, 2006.

Direito Penal Brasileiro: teoria geral do direito penal. $3^{\mathrm{a}}$. ed. Rio de Janeiro:

Data de recebimento: 03.06.2020

Data de aprovação: 08.08.2020 